\title{
MTHFR polymorphisms and serum cobalamin affect plasma homocysteine concentrations differentially in females and males
}

\author{
TORBJÖRN K. NILSSON ${ }^{1}$, ANNA K. BÖTTIGER ${ }^{2}$, PATRICIA HENRÍQUEZ ${ }^{3}$ and LLUÍS SERRA MAJEM ${ }^{3}$ \\ ${ }^{1}$ Department of Medical Biosciences, Clinical Chemistry, Umeå University, Umeå SE-90185; \\ ${ }^{2}$ Department of Laboratory Medicine, Clinical Chemistry, Örebro University Hospital, Örebro \\ SE-70185, Sweden; ${ }^{3}$ Nutrition Research Group, Research Institute of Biomedical and Health Sciences, \\ University of Las Palmas of Gran Canaria, Las Palmas 35016, Canary Islands, Spain
}

Received September 18,2013; Accepted May 9, 2014

DOI: $10.3892 / \mathrm{mmr} .2014 .2521$

\begin{abstract}
A total of 523 subjects (297 females and 226 males) from the Canary Islands Nutrition Study (ENCA) were studied in order to examine the effect of the MTHFR $677 \mathrm{C}>\mathrm{T}, 1298 \mathrm{~A}>\mathrm{C}$ and $1793 \mathrm{G}>\mathrm{A}$ polymorphisms, adjusted for age, serum (S)-folate and S-cobalamin levels, on total plasma homocysteine concentrations (tHcy). Genotyping was performed with Pyrosequencing ${ }^{\circledR}$ technology. The MTHFR 677T-allele was associated with increased tHcy concentrations only in males $(\mathrm{P}=0.005)$. The MTHFR $1298 \mathrm{C}$-allele was found to be associated with higher tHcy levels but similarly, only in males $(\mathrm{P}=0.025)$. The MTHFR 1793A-allele was associated with decreased tHcy concentrations in the younger males $(\mathrm{P}=0.042)$. A haplotype-based approach was marginally superior in explaining the genetic interaction of the MTHFR polymorphisms on tHcy plasma levels $\left(\mathrm{R}^{2} 0.352\right.$ vs. 0.342 for a simple genotype-based approach). A nutrigenetic interaction between the MTHFR $677 \mathrm{C}>\mathrm{T}$ genotype and S-cobalamin on tHcy levels was demonstrated in both genders. The increase in tHcy was more pronounced with decreasing S-cobalamin quintiles in 677TT homozygotes ( $\mathrm{P}=0.005$ for males and $\mathrm{P}=0.015$ for females) than with decreasing $\mathrm{S}$-folate quintiles ( $\mathrm{P}$ for trend not significant). It was concluded that gene-nutrient interactions may differ depending on the sex and age of the subjects. The transferability of gene-nutrient interactions from one community to others may therefore be limited not only by different food patterns but also by different ages, genders and genotype distributions.
\end{abstract}

Correspondence to: Professor Torbjörn K. Nilsson, Department of Medical Biosciences, Clinical Chemistry, Umeå University, Umeå SE-90185, Sweden

E-mail: torbjorn.nilsson@medbio.umu.se

Key words: MTHFR genotypes, haplotypes, total homocysteine, folate, cobalamin, nutrigenetics

\section{Introduction}

Methylenetetrahydrofolate reductase (MTHFR) is a key enzyme in the remethylation reaction, that catalyses the reduction of methylenetetrahydrofolate to methyltetrahydrofolate, which is the methyl donor for the conversion of homocysteine to methionine (1). An increased plasma total homocysteine (tHcy) is a risk marker for cardiovascular disease, neural tube defects and other birth defects (2). There is evidence that increased serum Hcy levels are associated with declining cognitive function and dementia (3). Deficiency of B vitamins, in particular folate, and/or mutations in genes coding for enzymes or proteins involved in metabolism, are major causes of elevated concentrations of tHcy (4-8). There are three universally common polymorphisms in the gene for MTHFR and two of them, 677C $>$ T (rs1801133) and 1298A $>C$ (rs1801131), are generally known to affect Hcy concentration to a varying degree $(1,5,9-13)$. However the third, $1793 \mathrm{G}>\mathrm{A}$ (rs2274976), is less common and has not been well studied, and thus whether it affects tHcy concentration remains controversial (14-16).

Subjects with the TT genotype have normal tHcy if their folate status is optimal (17). The 1298A $>$ C polymorphism is considered not to cause elevated tHcy concentrations, except when present with the 677T-allele in 'compound heterozygotes' $(18,19)$. Our previous study investigated the impact of MTHFR haplotypes on plasma tHcy concentrations in Swedish children and adolescents, and evidence was found for a tHcy-raising effect of the 1298C-allele and a tHcy-lowering effect of the 1793A-allele (20). It was hypothesised that in adults too, the haplotype-based approach in combination with data on serum (S)-folate and S-cobalamin levels would facilitate the elucidation of the impact of the MTHFR $1298 \mathrm{~A}>\mathrm{C}$ and $1793 \mathrm{G}>\mathrm{A}$ polymorphisms on thcy levels. The present study reports the findings in a representative epidemiological sample of healthy Spanish adult subjects from the Canary Islands.

\section{Materials and methods}

Subjects. The blood samples for DNA analysis were obtained from 723 subjects (395 females and 328 males) belonging to the Canary Islands Nutrition Study (ENCA). Serum samples 
were obtained from 523 subjects (297 females and 226 males). ENCA is a cross-sectional study from the Canary Islands (Spain) which was conducted to survey the nutritional status and selected metabolic and genetic variables of the population of the Canary Islands. The sampling procedures and participation rates have been described previously $(21,22)$. The present study was approved by the Research Ethics Committee of the Hospital Universitario Insular of Gran Canaria (Las Palmas, Canary Islands, Spain). Written informed consent was obtained from the participants.

Homocysteine and B vitamin analyses. As described previously (21), the blood samples were obtained in the morning after subjects had fasted for $12 \mathrm{~h}$. The S-folate levels were measured at the Haematology Unit of the Hospital Universitario Insular of Gran Canaria (Canary Islands, Spain) through an automated ionic capturing method with Abbott AXSYM equipment (Abbot, Berkshire, England, UK). Cobalamin was analysed via the micro-particle enzyme immune assay method with Abbott AXSYM equipment also at the Haematology Unit. Homocysteine was analysed at the University of Barcelona's Clinical Hospital (Barcelona, Spain), with polarized fluorescence immunoassay in an AXSYM (Abbot) analyser. The vitamin and tHcy values were available for 523 subjects.

DNA extraction and genotyping. Total blood DNA was extracted and purified from $200 \mu 1$ whole blood anticoagulated with EDTA, using the QIAamp DNA Blood Mini kit according to the manufacturer's instructions (Qiagen Inc., Valencia, CA, USA). The purity was assessed by the ratio of $\mathrm{A}_{280} / \mathrm{A}_{260}$, which was typically 1.7-1.8. All of the polymerase chain reaction amplifications were performed with HotStar Taq DNA polymerase kit (Qiagen Inc., Valencia, CA, USA) and an Eppendorf Mastercycler. The reaction volume was $50 \mu \mathrm{l}$ for all polymorphisms. MTHFR $677 \mathrm{C}>\mathrm{T}$ was amplified according to the Pyrosequencing ${ }^{\circledR}$ Assay Protocol 'Genotyping of the C677T variant in the human methylenetetrahydrofolate reductase (MTHFR) gene', version 1 (Biotage AB, Uppsala, Sweden; www.biotage.com). Approximately $30 \mathrm{ng}$ of genomic DNA was used as a template. For the MTHFR $1298 \mathrm{~A}>\mathrm{C}$ and $1793 \mathrm{G}>\mathrm{A}$ polymorphisms, our own genotyping procedures were used, using the Pyrosequencing platform as described previously (23).

Statistics. For examining of the Hardy-Weinberg equilibrium, a $\chi^{2}$ test was applied. Plasma tHcy, S-folate and S-cobalamin concentrations required transformation in order to achieve normal distribution. Following $\ln$ transformation, the residuals demonstrated a satisfactory pattern and $\ln$ values were used in all statistical analyses. In all tables and figures, untransformed data are provided.

Analysis of covariance (ANCOVA) was used to examine differences in tHcy between the age groups, gender, $\ln \mathrm{S}$-folate, In S-cobalamin and the MTHFR genotypes and haplotypes. Gender had a significant effect on tHcy concentrations and therefore the subjects were stratified by gender. Age group, In S-folate and ln S-cobalamin all had a significant effect on the tHcy levels and therefore all ANCOVA calculations adjusted for age in four groups (18-25, 25-45, 45-55 and 65-75 years), $\ln \mathrm{S}$-folate and $\ln \mathrm{S}$-cobalamin. It was previously found in this cohort that alcohol intake, smoking and BMI did not predict homocysteine concentrations (21), therefore these variables were not included in the present study.

When analysing one genotype's effect on tHcy, adjustments were made for the other two MTHFR genotypes, either by including them in the ANCOVA's or by stratification, as indicated. Since S-folate and S-cobalamin levels did not differ between males and females, cut-offs for quintiles were generated using all of the subjects. Logistic regression was performed for analysis of the effect of MTHFR 677TT genotype on S-cobalamin levels. S-cobalamin was stratified into two groups below and above $150 \mathrm{pmol} / \mathrm{l}$, which has been previously suggested as a cut-off level for deficiency (24). All of the mean values are estimated marginal means. To examine for a linear trend in ln tHcy concentrations between quintiles of S-folate or S-cobalamin in the subgroups MTHFR 677 $\mathrm{CC}+\mathrm{CT}$ or MTHFR 677TT, one way ANOVA was performed. Statistical significance was interpreted as values of $\mathrm{P}<0.05$ and confidence intervals at $95 \%$. Statistical analyses were performed using SPSS 15.0 for Windows (SPSS, Inc., Chicago, IL, USA).

\section{Results}

MTHFR genotypes and haplotypes. Basic clinical characteristics of the studied population have been published previously (21). Briefly, noted characteristics of the population were as follows: there was a significant difference in median tHcy between males and females (13.1 and $10.9 \mu \mathrm{mol} / 1$, respectively) and also in median folate intake between males and females (161.6 and $141.9 \mu \mathrm{g} /$ day, respectively); there were no significant differences for cobalamin intake, S-folate, erythrocyte folate or S-cobalamin. The genotype prevalences and allele frequencies for all three studied MTHFR polymorphisms in the 723 ENCA subjects are revealed in Table I. All loci were in Hardy-Weinberg equilibrium when analysing the entire population.

The frequency of the MTHFR $677 \mathrm{~T}$ minor allele was $\mathrm{q}=0.357$ and 0.360 , respectively, in subjects below and above 40 years of age $\left(\chi^{2}=0.01\right)$. In females aged below and above 40 years of age, the frequency of the MTHFR 677T-allele was $\mathrm{q}=0.377$ and 0.356 , respectively $\left(\chi^{2}=0.76\right)$, and in males below and above 40 years of age the frequency was $q=0.333$ and 0.364 , respectively $\left(\chi^{2}=1.13\right)$.

tHcy and MTHFR genotypes or haplotypes. A one-way ANCOVA was performed with MTHFR $677 \mathrm{C}>\mathrm{T}$ as the fixed factor and gender, age in the four groups, $\ln \mathrm{S}$-folate, In S-cobalamin, and genotypes of MTHFR 1298A $>\mathrm{C}$ and $1793 \mathrm{G}>\mathrm{A}$ as covariates. Adjusted $\mathrm{R}^{2}$ for the model was 0.333 . The MTHFR $677 \mathrm{C}>\mathrm{T}$ polymorphism demonstrated a statistically significant interaction with gender $(\mathrm{P}=0.02)$ so in the following studies the results were therefore stratified according to gender. Adjusted for covariates, the MTHFR $677 \mathrm{C}>\mathrm{T}$ polymorphism had a significant effect on tHcy in males $(\mathrm{P}=0.005)$ and adjusted $\mathrm{R}^{2}$ for the model was 0.342 . Adjusted for covariates, the MTHFR $677 \mathrm{C}>\mathrm{T}$ had no significant effect in females.

To isolate the single effect of the MTHFR 1298A >C polymorphism on tHcy, a one-way ANCOVA was performed separately in the genotype groups $677 \mathrm{CC}$ and $677 \mathrm{CT}$, with 
Table I. Genotype prevalences and allele frequencies of the three studied MTHFR polymorphisms in 723 subjects in the Canary Islands Nutrition study from the Canary Islands (Spain).

\begin{tabular}{lccc}
\hline Polymorphism & Genotype & Frequency & $\chi^{2}$ \\
\hline $677 \mathrm{C}>\mathrm{T}$ & $\mathrm{C} / \mathrm{C}$ & $291(40.2)$ & 1.203 \\
& $\mathrm{C} / \mathrm{T}$ & $346(47.9)$ & \\
$\mathrm{T} / \mathrm{T}$ & $86(11.9)$ & \\
& $\mathrm{p}(\mathrm{C})$ & $928(0.642)$ & \\
& $\mathrm{q}(\mathrm{T})$ & $518(0.358)$ & \\
1298A $>\mathrm{C}$ & $\mathrm{A} / \mathrm{A}$ & $384(53.1)$ & 0.026 \\
& $\mathrm{~A} / \mathrm{C}$ & $287(39.7)$ & \\
& $\mathrm{C} / \mathrm{C}$ & $52(7.2)$ & \\
& $\mathrm{p}(\mathrm{A})$ & $1055(0.730)$ & \\
& $\mathrm{q}(\mathrm{C})$ & $391(0.270)$ & \\
& $\mathrm{G} / \mathrm{G}$ & $687(95.0)$ & 0.471 \\
& $\mathrm{G} / \mathrm{A}$ & $36(5.0)$ & \\
& $\mathrm{A} / \mathrm{A}$ & $-(-)$ & \\
& $\mathrm{p}(\mathrm{G})$ & $1410(0.975)$ & \\
& $\mathrm{q}(\mathrm{A})$ & $36(0.025)$ & \\
\hline
\end{tabular}

The number of subjects and percentages are demonstrated, as well as $\chi^{2}$ for Hardy-Weinberg equilibrium testing. For alleles, the number of alleles and percentages are expressed.

$1298 \mathrm{~A}>\mathrm{C}$ as a fixed factor and age in the four groups, In $\mathrm{S}$-folate, and In S-cobalamin as covariates (Table II). The $1298 \mathrm{~A}>\mathrm{C}$ polymorphism had a significant effect on tHcy in males with the 677CT genotype, with a mean tHcy of $1.7 \mu \mathrm{mol} / \mathrm{l}$ higher than the 1298AA wildtype subjects. In males with the $677 \mathrm{CC}$ genotype, $1298 \mathrm{~A}>\mathrm{C}$ had no significant effect on tHcy concentrations. In females, there was no significant effect of MTHFR 1298A >C on tHcy concentrations.

To investigate the effect of the MTHFR $1793 \mathrm{G}>\mathrm{A}$ polymorphism on tHcy concentrations, one-way ANCOVA's were performed with the diplotypes CCG/CCG and CCG/CCA as fixed factors and age in the four groups, $\ln \mathrm{S}$-folate and $\mathrm{ln}$ $\mathrm{S}$-cobalamin as covariates. There was no significant effect on tHcy of the MTHFR $1793 \mathrm{G}>\mathrm{A}$ genotype in neither females nor males, but the sample number of subjects was small. When the study population was stratified in younger vs. older subjects (below and above 52 years of age according to the mean age of menopause) and MTHFR $677 \mathrm{C}>\mathrm{T}$ genotype (CC+CT vs. TT) ANCOVA (with MTHFR 1298A >C, ln S-folate and ln S-cobalamin as cofactors) demonstrated a significant Hcy-lowering effect of the MTHFR 1793 GA genotype in males $<52$ years, with a mean of $2.4 \mu \mathrm{mol} / 1$ lower than the males with the MTHFR 1793 GG genotype (Table III).

To investigate the effect of the MTHFR haplotypes on tHcy, ANCOVA was performed with In tHcy as a dependent factor, haplotype was entered as fixed factor, and age in the four groups, In S-folate and In S-cobalamin were entered as covariates. With the two-locus haplotypes 677T-1298A and
Table II. tHcy concentrations according to MTHFR 1298A >C genotype in subjects with the MTHFR 677 CC or CT genotype.

\begin{tabular}{lcccc}
\hline Subjects & Genotype & No. & Mean $(95 \% \mathrm{CI})$ & P-value \\
\hline Females $(\mathrm{n}=250)$ & & & & \\
677 CC & 1298 AA & 35 & $12.2(11.3-13.2)$ & 0.187 \\
& $1298 \mathrm{AC}$ & 51 & $11.2(10.4-11.9)$ & \\
& $1298 \mathrm{CC}$ & 15 & $11.1(9.6-12.5)$ & \\
$677 \mathrm{CT}$ & $1298 \mathrm{AA}$ & 93 & $11.7(11.1-12.4)$ & 0.702 \\
& $1298 \mathrm{AC}$ & 56 & $11.1(10.8-12.4)$ & \\
Males (n=183) & & & & \\
677 CC & $1298 \mathrm{AA}$ & 35 & $13.2(12.2-14.2)$ & 0.423 \\
& $1298 \mathrm{AC}$ & 41 & $12.9(12.0-13.8)$ & \\
& $1298 \mathrm{CC}$ & 9 & $14.8(12.8-16.7)$ & \\
677 CT & $1298 \mathrm{AA}$ & 59 & $13.6(12.5-14.6)$ & 0.025 \\
& $1298 \mathrm{AC}$ & 39 & $15.3(14.1-16.6)$ & \\
\hline
\end{tabular}

Subjects with the 1793GA genotype were excluded. Mean and 95\% CI $(\mu \mathrm{mol} / \mathrm{l})$ are demonstrated. P-values calculated with ln-transformed tHcy values. All of the values were adjusted for age in four groups, $\ln$ S-folate and ln S-cobalamin. tHcy, total plasma homocysteine; CI, confidence interval; $\mathrm{S}$, serum levels.

677C-1298C as fixed factors, an $\mathrm{R}^{2}$ of 0.352 was obtained in males $(\mathrm{P}=0.013)$ for the TA haplotype whereas in females, no haplotype was significantly correlated with tHcy. In a similar ANCOVA utilizing the three-locus haplotypes, 677T-1298A-1793G and 677C-1298C-1793G as fixed factors, no additional power over that of the MTHFR $677 \mathrm{C}>\mathrm{T}$ genotype was obtained. The haplotype containing the mutated 1793A-allele was excluded from the analysis due to its low prevalence. Fig. 1 summarizes the mean tHcy concentrations in all the different diplotype subgroups.

tHcy and nutrigenetic interactions. S-cobalamin was divided into groups of above and below $150 \mathrm{pmol} / \mathrm{l}$ and logistic regression was performed to elucidate the effect of $M T H F R$ $677 \mathrm{TT}$ on S-cobalamin. It was revealed that the MTHFR $677 \mathrm{TT}$ genotype was not statistically significantly associated with S-cobalamin.

Fig. 2 reveals that the mean tHcy levels increased with lower quintiles of S-folate, statistically significantly in the MTHFR $677 \mathrm{CC}+\mathrm{CT}$ subgroups ( $\mathrm{P}<0.001$ for both genders). The mean difference between $\mathrm{Q}_{1}$ and $\mathrm{Q}_{5}$ in males was $+4.0 \mu \mathrm{mol} / 1$ in the CC+CT subgroup and $+18.8 \mu \mathrm{mol} / 1$ in the TT subgroup, and in females it was $+3.8 \mu \mathrm{mol} / 1$ in the $\mathrm{CC}+\mathrm{CT}$ subgroup and $-3.6 \mu \mathrm{mol} / \mathrm{l}$ for the TT group.

Fig. 3 demonstrates that the mean tHcy levels also increased with lower quintiles of S-cobalamin. In the MTHFR $677 \mathrm{CC}+\mathrm{CT}$ subgroup, $\mathrm{P}<0.001$ for males and $\mathrm{P}=0.005$ for females; in the MTHFR 677TT subgroup, $\mathrm{P}=0.005$ for males and $\mathrm{P}=0.015$ for females. The mean tHcy difference in males between the cobalamin quintiles $\mathrm{Q}_{1}$ and $\mathrm{Q}_{5}$ was $+4.6 \mu \mathrm{mol} / 1$ in the $\mathrm{CC}+\mathrm{CT}$ subgroup and $+21 \mu \mathrm{mol} / 1$ in the TT subgroup, and in females it was $+1.8 \mu \mathrm{mol} / 1$ in the $\mathrm{CC}+\mathrm{CT}$ subgroup and $+4.6 \mu \mathrm{mol} / 1$ in the TT subgroup. 
Table III. tHcy concentrations according to MTHFR $1793 \mathrm{G}>\mathrm{A}$ genotype in males and females below and above 52 years old. Stratified according to MTHFR 677C $>$ T genotype.

\begin{tabular}{|c|c|c|c|c|c|}
\hline Sex & Age (years & MTHFR 677 genotype & MTHFR $1793 \mathrm{G}>\mathrm{A}$ & Mean $(95 \% \mathrm{CI})$ & P-value \\
\hline \multirow[t]{3}{*}{ Males } & \multirow[t]{3}{*}{$<52$} & \multirow[t]{2}{*}{$\mathrm{CC}+\mathrm{CT}$} & GG & $12.7(12.1-13.2)$ & \multirow[t]{3}{*}{0.042} \\
\hline & & & GA & $10.2(8.0-12.5)$ & \\
\hline & & $\mathrm{TT}$ & GG & $21.7(14.9-28.5)$ & \\
\hline \multirow[t]{3}{*}{ Males } & \multirow[t]{3}{*}{$>52$} & \multirow{2}{*}{$\mathrm{CC}+\mathrm{CT}$} & GG & $15.5(14.6-16.5)$ & \multirow[t]{3}{*}{0.742} \\
\hline & & & GA & $16.2(12.3-20.1)$ & \\
\hline & & $\mathrm{TT}$ & GG & $15.5(11.1-19.9)$ & \\
\hline \multirow[t]{3}{*}{ Females } & \multirow[t]{3}{*}{$<52$} & \multirow{2}{*}{$\mathrm{CC}+\mathrm{CT}$} & GG & $10.9(10.5-11.4)$ & \multirow[t]{3}{*}{0.920} \\
\hline & & & GA & $11.0(9.2-12.9)$ & \\
\hline & & $\mathrm{TT}$ & GG & $11.6(9.9-13.3)$ & \\
\hline \multirow[t]{3}{*}{ Females } & \multirow[t]{3}{*}{$>52$} & $\mathrm{CC}+\mathrm{CT}$ & GG & $13.0(12.3-13.7)$ & \multirow[t]{3}{*}{0.447} \\
\hline & & & GA & $12.0(9.3-14.6)$ & \\
\hline & & TT & GG & $12.3(10.3-14.3)$ & \\
\hline
\end{tabular}

Mean and $95 \% \mathrm{CI}(\mu \mathrm{mol} / \mathrm{l})$ are demonstrated. P-values are calculated with ln-transformed tHcy values. All values were adjusted for MTHFR $1298 \mathrm{~A}>\mathrm{C}$ ln S-folate and ln S-cobalamin. tHcy, total plasma homocysteine; S, serum levels; 95\% CI, 95\% confidence interval.
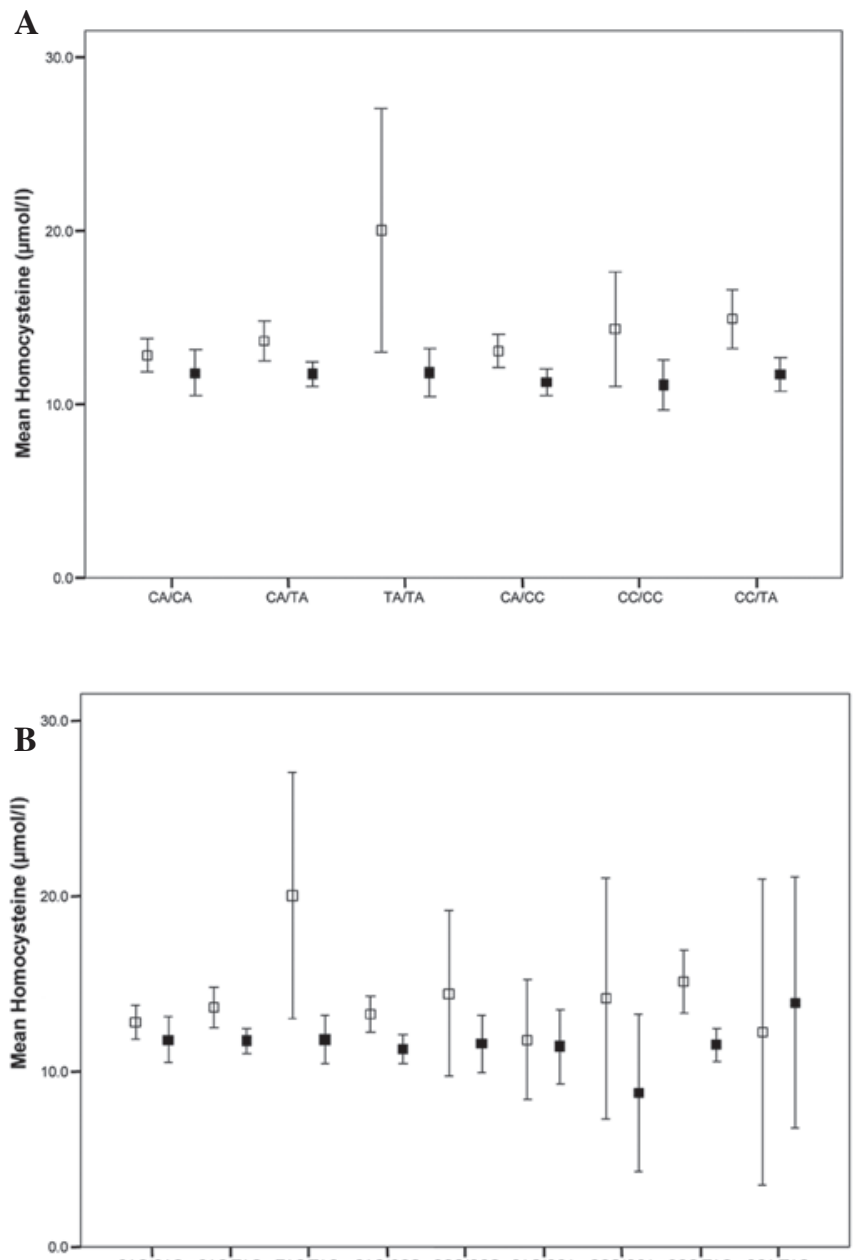

Figure 1. tHcy in relation to diplotypes of the MTHFR $677 \mathrm{C}>\mathrm{T}, 1298 \mathrm{~A}>\mathrm{C}$ and $1793 \mathrm{G}>\mathrm{A}$ polymorphisms. (A) The two-locus system (MTHFR $677 \mathrm{C}>\mathrm{T}$ and 1298A $>$ C); (B) The three-locus system (MTHFR 677C $>$ T, 1298A $>C$ and $1793 \mathrm{G}>\mathrm{A}$ ). Filled squares represent the females; open squares represent the males. The mean levels are demonstrated and the whiskers denote the $95 \%$ confidence interval.

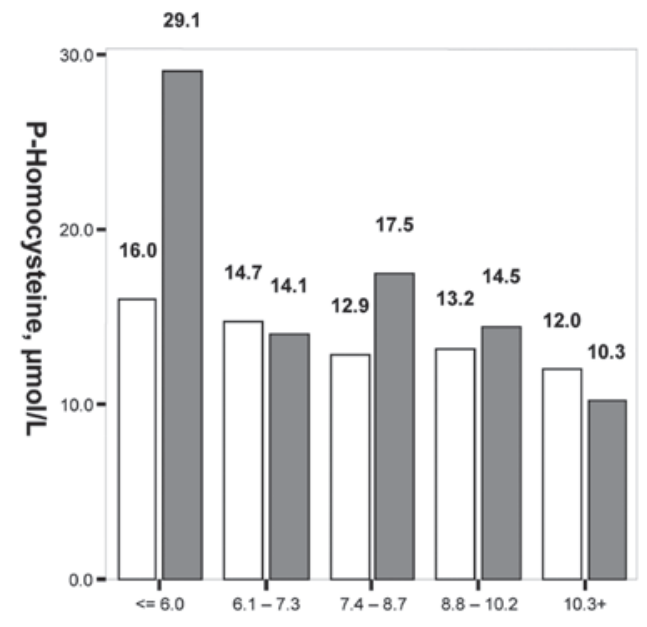

Quintiles S-Folate

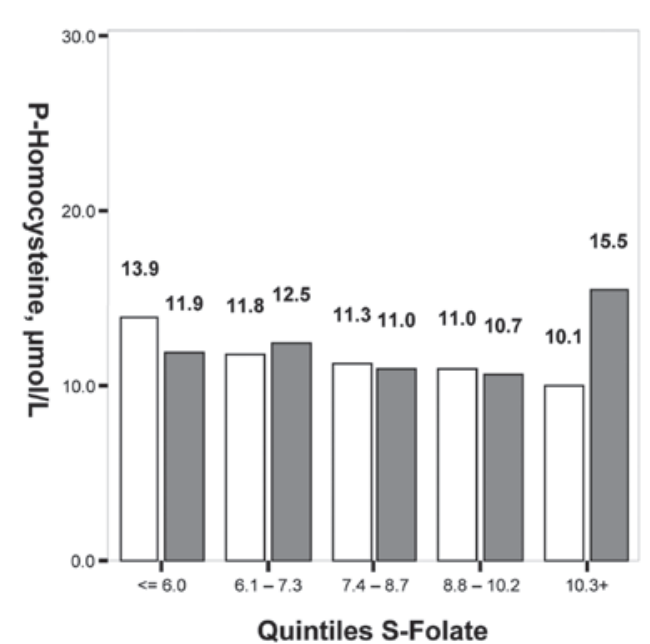

Figure 2. tHcy mean values in relation to quintiles of S-folate (nmol/l) in males (upper panel) and females (lower panel) according to $M T H F R$ 677C $>\mathrm{T}$ genotypes. Open bars: MTHFR $677 \mathrm{CC}+\mathrm{CT}$ subjects. Shaded bars: MTHFR 677 TT subjects. tHcy, total plasma homocysteine; S, serum levels. 
A

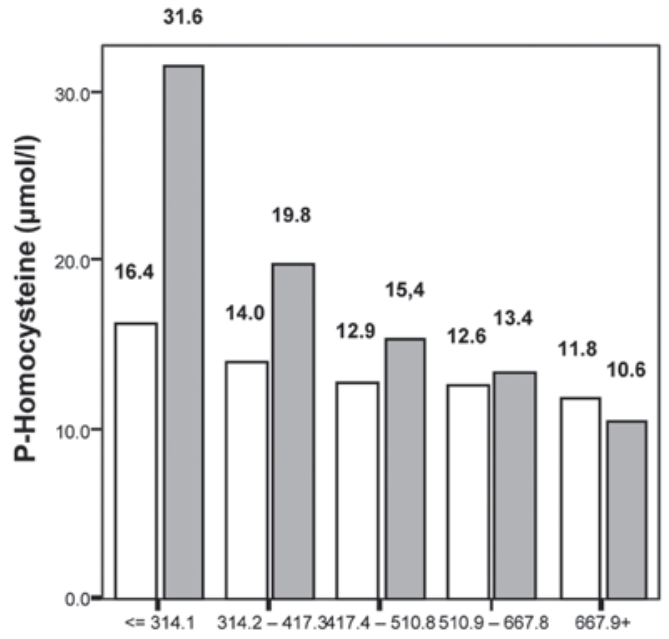

Quintiles S-Cobalamin

B

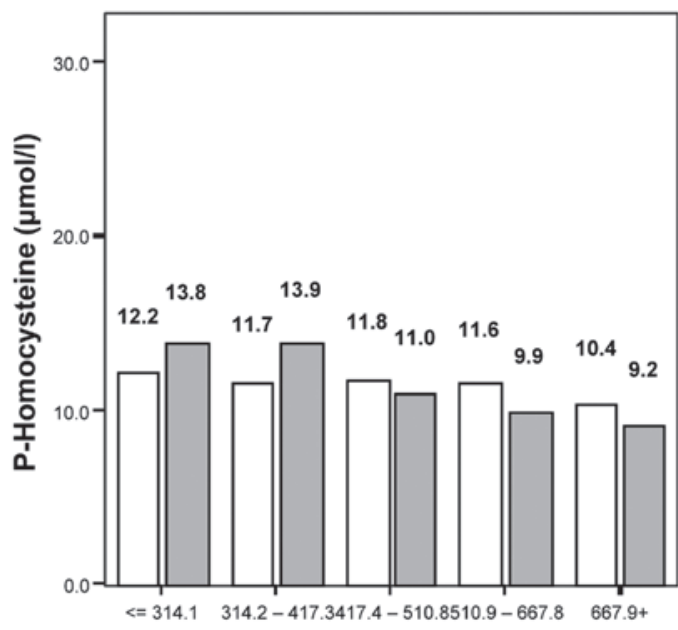

Quintiles S-Cobalamin

Figure 3. tHcy mean values in relation to the quintiles of S-cobalamin (pmol/1) in (A) males and (B) females according to MTHFR 677C $>\mathrm{T}$ genotypes. Open bars: MTHFR $677 \mathrm{CC}+\mathrm{CT}$ subjects. Shaded bars: MTHFR 677 TT subjects; S, serum levels.

tHcy in pre-and postmenopausal females. The female subjects were divided into two groups, below and above 52 years of age and ANCOVA was performed (Table IV). There was a significant difference in tHcy concentrations between the two age groups $(\mathrm{P}<0.001)$. None of the polymorphisms MTHFR $677 \mathrm{C}>\mathrm{T}, 1298 \mathrm{~A}>\mathrm{C}$ and $1793 \mathrm{G}>\mathrm{A}$ were significantly correlated with tHcy in the two groups (data not shown).

\section{Discussion}

The present study aimed to clarify the nutrigenetic impact on tHcy concentrations of the MTHFR genotypes and haplotypes adjusted for the known covariates age, sex and serum concentration of folate and cobalamin in the Spanish adult population. Within this population, tHcy levels are known to be dependent on both these vitamins (21).

Our allele figures for the MTHFR $677 \mathrm{C}>\mathrm{T}$ polymorphism are consistent with another study, which investigated the prevalence of MTHFR $677 \mathrm{C}>\mathrm{T}$ in Spain (25). A study from Majorca (26) reported different frequencies of the $\mathrm{q}$ allele
Table IV. tHcy concentrations in females and males below and above 52 years old.

\begin{tabular}{lccc}
\hline Age (years) & no. & Mean $(95 \% \mathrm{CI})$ & P-value \\
\hline $\begin{array}{l}\text { Females } \\
<52\end{array}$ & 194 & $10.8(10.4-11.2)$ & $<0.001$ \\
$>52$ & 103 & $13.2(12.6-13.8)$ & \\
$\begin{array}{l}\text { Males } \\
<52\end{array}$ & 140 & $14.4(13.2-15.6)$ & 0.006 \\
$>52$ & 86 & $14.9(13.3-16.4)$ & \\
\hline
\end{tabular}

Mean and $95 \% \mathrm{CI}(\mu \mathrm{mol} / \mathrm{l})$ are demonstrated. P-values calculated with $\ln$-transformed tHcy values. All values were adjusted for $\ln$ S-folate and ln S-cobalamin. tHcy, total plasma homocysteine; 95\% CI, 95\% confidence interval; S, serum levels.

between younger and elderly subjects, a genetically implausible finding not supported by the present data from the Canary Islands, or a study comparing the MTHFR 677T-allele frequencies between newborn and $>80$-year-old Swedish subjects, which were found to be $\mathrm{q}=0.291$ and 0.270 , respectively (27). The present figures on q among younger (below 40 years) vs. elderly (above 40 years) differed only marginally and in a way that evidently invites to the assumption of 'regression towards the mean'.

In the present study, an important finding was the significant gender difference in the effect of the MTHFR $677 \mathrm{C}>\mathrm{T}$ polymorphism on tHcy concentrations, as is consistent with several other studies (28-30). In Spanish females with the MTHFR 677TT genotype, the reduced levels of 5'-methyl-tetrahydrofolate did not affect tHcy levels if adjusted for major covariates. One possible explanation may be estrogen. Lower levels of tHcy are observed in pregnant females, and in premenopausal and postmenopausal females undergoing hormone replacement therapy (31) (Table IV). Estrogen induces the expression of the gene for phosphatidylethanolamine $\mathrm{N}$-methyltransferase (PEMT) which catalyzes the biosynthesis of phosphatidylcholine, a precursor for betaine. Betaine is an alternative source of methyl groups in the remethylation process of Hcy, and it has been proposed that premenopausal females may supply choline from endogenous biosynthesis (32). By contrast, it has been noted that deletion of the PEMT gene in mice reduces Hcy levels by $50 \%$ (33), which would argue against estrogen induction of PEMT as an explanation of the present findings. When the effect of the 677T-allele on tHcy in Swedish children and adolescents was studied, a significant tHcy-raising effect of the T-allele in girls was identified, but it was of smaller magnitude in $\mu \mathrm{mol} / \mathrm{l}$ than in the boys of the same ages (20). Yang et al demonstrated that the adverse impact of the MTHFR 677TT genotype on homocysteine concentrations was attenuated by dietary folate intake (34), but in this cohort females actually have lower folate intake than males (21) which precludes this as an explanation. Therefore, the causes of the described male/female differences remain elusive and it may well be that alternative food sources (for instance, choline) contributing to the methyl group balance, unaccounted for in this as well as in the majority of other epidemiological studies, may explain, 
in part, such gender differences (33). Other studies have also demonstrated that the effect of the MTHFR $677 \mathrm{C}>\mathrm{T}$ polymorphism may vary between populations, for example, people in Mexico City have a high prevalence of the MTHFR $677 \mathrm{C}>\mathrm{T}$ polymorphism but they also have a low influence of the polymorphism on Hcy concentrations (35).

Notably, another finding was that in the subjects with the MTHFR 677TT genotype, there was an interaction of tHcy with not only low S-folate, but also with low S-cobalamin (Fig. 3) as has also been observed in other studies (24,36-38). The association of low S-cobalamin with increased tHcy was more robust than that of low $\mathrm{S}$-folate (Figs. 2 and 3). The subjects with the MTHFR 677TT genotype raised their tHcy levels quantitatively more with lower cobalamin quintiles than did subjects with the $677 \mathrm{CC}$ or $\mathrm{CT}$ genotypes, and the effect was of a greater magnitude (in $\mu \mathrm{mol} / \mathrm{l}$ ) in males than in females.

The findings suggest that in the Canary Islands both folate and cobalamin are major tHcy-determinants in both males and females, and both vitamins should be included in nutrigenetic studies on MTHFR $677 \mathrm{C}>\mathrm{T}$, often regarded as biochemically responsive only to $\mathrm{S}$-folate levels.

The MTHFR 1793A-allele was in complete linkage disequilibrium with the $1298 \mathrm{C}$-allele. Consistent with our previous Swedish study (20), it was identified that the 1793 A-allele has a lowering effect on tHcy levels, however in this study it was only statistically significant in males $<52$ years of age. The 1298A >C polymorphism had a minor elevating effect on tHcy in males, who were 677CT/1298AC compound heterozygotes.

Nutrigenetic interactions and their effect on biomarkers are commonly overlooked. Nevertheless, even small effects may be uncovered in well-characterized populations and, as it appears from our studies, in younger populations and particularly in males. Several body functions decrease with age, e.g. glomerular filtration rate and tubular function which raise tHcy concentrations. In addition, the older population may be taking vitamin supplementation or drugs affecting Hcy metabolism, for instance, Spaniards $>65$ years of age take a mean of three or more different medications per day $(39,40)$.

Haplotypes from the MTHFR polymorphisms $677 \mathrm{C}>\mathrm{T}$, $1298 \mathrm{~A}>\mathrm{C}$ and $1793 \mathrm{G}>\mathrm{A}(\mathrm{CAG}, \mathrm{TAG}, \mathrm{CCG}, \mathrm{CCA})$ were constructed and their impact on tHcy was analysed. A small additional explanatory power for tHcy concentrations was obtained using the 677-1298 two-locus haplotype system above that which was provided by the MTHFR $677 \mathrm{C}>\mathrm{T}$ genotype alone. In our previous study in children, the best explanatory power was obtained by the three locus haplotype (20). It is therefore suggested that, when investigating the association of the MTHFR polymorphisms to tHcy in a population sample, the MTHFR haplotypes should be examined in the calculations and not just the genotypes.

Based on the above results and the findings of our previous study (20), the following set of nutrigenetic statements for the Hcy metabolism are proposed: (i) age, sex and factors linked to the ethnicity of the studied subjects, appear to be able to override the nutrigenetic impact of tHcy-raising MTHFR genotypes or haplotypes in particular settings, exemplified here by Spanish adult females; (ii) gene-nutrient interactions on plasma tHcy levels thus may or may not exist in a certain population; (iii) the transferability of nutrigenetic findings between different communities may therefore be limited, and may possibly need to be re-evaluated for each particular community according to age, sex and ethnicity.

In conclusion, the major genetic impact on tHcy concentrations in Spanish subjects was attributable to the MTHFR $677 \mathrm{C}>\mathrm{T}$ polymorphism but in the full cohort the effect was limited to males only. A haplotype based analysis was marginally superior to genotype based analyses in accounting for the MTHFR impact on tHcy. A nutrigenetic interaction with low S-cobalamin was also demonstrated: in subjects with the lowest $\mathrm{S}$-cobalamin levels, the tHcy increase was higher among 677 TT homozygotes than in subjects with the $677 \mathrm{CC}$ or CT genotypes and the magnitude of this effect was more pronounced in males.

\section{Acknowledgements}

This study was supported by grants from Nyckelfonden, Örebro, Sweden and Forskningskommitteén, Örebro County Council, Sweden. The authors are grateful to Margareta Karlsson for technical assistance and Anita Hurtig-Wennlöf for generous comments as the manuscript evolved. Authors thank the Canarian Health Service for facilitating all the data from the ENCA (Canarian Nutrition Survey).

\section{References}

1. Yamada K, Chen Z, Rozen R and Matthews RG: Effects of common polymorphisms on the properties of recombinant human methylenetetrahydrofolate reductase. Proc Natl Acad Sci USA 98: 14853-14858, 2001.

2. Bolander-Gouaille C and Bottiglieri T (eds): Homocysteine Related Vitamins and Neuropsychiatric Disorders. Springer, Paris, 2003.

3. Garcia A and Zanibbi K: Homocysteine and cognitive function in elderly people. CMAJ 171: 897-904, 2004.

4. Blom HJ: Determinants of plasma homocysteine. Am J Clin Nutr 67: 188-189, 1998.

5. Frosst P, Blom HJ, Milos R, Goyette P, Sheppard CA, Matthews RG, Boers GJ, den Heijer M, Kluijtmans LA, van den Heuvel LP, et al: A candidate genetic risk factor for vascular disease: a common mutation in methylenetetrahydrofolate reductase. Nat Genet 10: 111-113, 1995.

6. Lievers KJ, Boers GH, Verhoef P, den Heijer M, Kluijtmans LA, van der PutNM, Trijbels FJ and Blom HJ: A second common variant in the methylenetetrahydrofolate reductase (MTHFR) gene and its relationship to MTHFR enzyme activity, homocysteine, and cardiovascular disease risk. J Mol Med (Berl) 79: 522-528, 2001.

7. Mudd SH, Uhlendorf BW, Freeman JM, Finkelstein JD and Shih VE: Homocystinuria associated with decreased methylenetetrahydrofolate reductase activity. Biochem Biophys Res Commun 46: 905-912, 1972.

8. Selhub J: Homocysteine metabolism. Annu Rev Nutr 19: 217-246, 1999.

9. van der Put NM, Gabreëls F, Stevens EM, Smeitink JA, Trijbels FJ, Eskes TK, van den Heuvel LP and Blom HJ: A second common mutation in the methylenetetrahydrofolate reductase gene: an additional risk factor for neural-tube defects? Am J Hum Genet 62: 1044-1051, 1998.

10. Weisberg I, Tran P, Christensen B, Sibani S and Rozen R: A second genetic polymorphism in methylenetetrahydrofolate reductase (MTHFR) associated with decreased enzyme activity. Mol Genet Metab 64: 169-172, 1998.

11. Viel A, Dall'Agnese L, Simone F, Canzonieri V, Capozzi E, Visentin MC, Valle R and Boiocchi M: Loss of heterozygosity at the 5,10-methylenetetrahydrofolate reductase locus in human ovarian carcinomas. Br J Cancer 75: 1105-1110, 1997. 
12. de Bree A, Verschuren WM, Bjørke-Monsen AL, van der Put NM, Heil SG, Trijbels FJ and Blom HJ: Effect of the methylenetetrahydrofolate reductase $677 \mathrm{C}-->\mathrm{T}$ mutation on the relations among folate intake and plasma folate and homocysteine concentrations in a general population sample. Am J Clin Nutr 77: 687-693, 2003.

13. Cortese C and Motti C: MTHFR gene polymorphism, homocysteine and cardiovascular disease. Public Health Nutr 4: 493-497, 2001.

14. Huemer M, Vonblon K, Födinger M, Krumpholz R, Hubmann M, Ulmer $\mathrm{H}$ and Simma B: Total homocysteine, folate, and cobalamin, and their relation to genetic polymorphisms, lifestyle and body mass index in healthy children and adolescents. Pediatr Res 60: 764-769, 2006.

15. Rady PL, Szucs S, Grady J, Hudnall SD, Kellner LH, Nitowsky H, Tyring SK and Matalon RK: Genetic polymorphisms of methylenetetrahydrofolate reductase (MTHFR) and methionine synthase reductase (MTRR) in ethnic populations in Texas; a report of a novel MTHFR polymorphic site, G1793A. Am J Med Genet 107: 162-168, 2002.

16. Wakutani Y, Kowa H, Kusumi M, Nakaso K, Yasui K, Isoe-Wada $\mathrm{K}$, Yano $\mathrm{H}$, Urakami $\mathrm{K}$, Takeshima $\mathrm{T}$ and Nakashima K: A haplotype of the methylenetetrahydrofolate reductase gene is protective against late-onset Alzheimer's disease. Neurobiol Aging 25: 291-294, 2004.

17. Guenther BD, Sheppard CA, Tran P, Rozen R, Matthews RG and Ludwig ML: The structure and properties of methylenetetrahydrofolate reductase from Escherichia coli suggest how folate ameliorates human hyperhomocysteinemia. Nat Struct Biol 6 : 359-365, 1999.

18. Isotalo PA, Wells GA and Donnelly JG: Neonatal and fetal methylenetetrahydrofolate reductase genetic polymorphisms: an examination of C677T and A1298C mutations. Am J Hum Genet 67: 986-990, 2000

19. Weisberg IS, Jacques PF, Selhub J, Bostom AG, Chen Z, Curtis Ellison R, Eckfeldt JH and Rozen R: The 1298A-->C polymorphism in methylenetetrahydrofolate reductase (MTHFR) in vitro expression and association with homocysteine. Atherosclerosis 156: 409-415, 2001

20. Böttiger AK, Hurtig-Wennlöf A, Sjöström M, Yngve A and Nilsson TK: Association of total plasma homocysteine with methylenetetrahydrofolate reductase genotypes $677 \mathrm{C}>\mathrm{T}$, $1298 \mathrm{~A}>\mathrm{C}$, and $1793 \mathrm{G}>\mathrm{A}$ and the corresponding haplotypes in Swedish children and adolescents. Int J Mol Med 19: 659-665, 2007.

21. Henríquez P, Doreste J, Deulofeu R, Fiuza MD and Serra-Majem L: Nutritional determinants of plasma total homocysteine distribution in the Canary Islands. Eur J Clin Nutr 61: 111-118, 2007.

22. Serra Majem L, Ribas Barba L, Armas Navarro A, Alvarez León E and Sierra A; Equipo de investigación de ENCA: Energy and nutrient intake and risk of inadequate intakes in Canary Islands (1997-98). Arch Latinoam Nutr 50 (Suppl 1): 7-22, 2000 (In Spanish).

23. Börjel AK, Yngve A, Sjöström M and Nilsson TK: Novel mutations in the 5'-UTR of the FOLR1 gene. Clin Chem Lab Med 44: 161-167, 2006.

24. Zittan E, Preis M, Asmir I, Cassel A, Lindenfeld N, Alroy S, Halon DA, Lewis BS, Shiran A, Schliamser JE and Flugelman MY: High frequency of vitamin B12 deficiency in asymptomatic individuals homozygous to MTHFR C677T mutation is associated with endothelial dysfunction and homocysteinemia. Am J Physiol Heart Circ Physiol 293: H860-H865, 2007.

25. Martínez-Frías ML, Bermejo E, Rodríguez-Pinilla E, Scala I, Andria $G$ and Botto L: Frequency of the mutation 677C-T of methylenetetrahydrofolate reductase gene on a sample of 652 Spanish liveborn infants. Med Clin (Barc) 122: 361-364, 2004 (In Spanish).
26. Martín I, Obrador A, Gibert MJ, Hernanz A, Fuster A, Pintos C, Garcia A and Tur J: Folate status and a new repletion cut-off value in a group of healthy Majorcan females. Clin Nutr 22: 53-58, 2003

27. Brattström L, Zhang Y, Hurtig M, Refsum H, Ostensson S, Fransson L, Jonés K, Landgren F, Brudin L and Ueland PM: A common methylenetetrahydrofolate reductase gene mutation and longevity. Atherosclerosis 141: 315-319, 1998.

28. Brown KS, Kluijtmans LA, Young IS, Murray L, McMaster D, Woodside JV, Yarnell JW, Boreham CA, McNulty H, Strain JJ, et al: The 5,10-methylenetetrahydrofolate reductase C677T polymorphism interacts with smoking to increase homocysteine. Atherosclerosis 174: 315-322, 2004.

29. Chango A, Potier De Courcy G, Boisson F, Guilland JC, Barbé F, Perrin MO, Christidès JP, Rabhi K, Pfister M, Galan P, et al: 5,10-methylenetetrahydrofolate reductase common mutations, folate status and plasma homocysteine in healthy French adults of the Supplemalestation en Vitamines et Mineraux Antioxydants (SU.VI.MAX) cohort. Br J Nutr 84: 891-896, 2000.

30. Kluijtmans LA, Young IS, Boreham CA, Murray L, McMaster D, McNulty H, Strain JJ, McPartlin J, Scott JM and Whitehead AS: Genetic and nutritional factors contributing to hyperhomocysteinemia in young adults. Blood 101: 2483-2488, 2003.

31. Dimitrova, KR, DeGroot K, Myers AK and Kim YD: Estrogen and homocysteine. Cardiovasc Res 53: 577-588, 2002.

32. Fischer LM, da Costa KA, Galanko J, Sha W, Stephenson B, Vick J and Zeisel SH: Choline intake and genetic polymorphisms influence choline metabolite concentrations in human breast milk and plasma. Am J Clin Nutr 92: 336-346, 2010.

33. Stead LM, Brosnan JT, Brosnan ME, Vance DE and Jacobs RL: Is it time to reevaluate methyl balance in humans? Am J Clin Nutr 83: 5-10, 2006

34. Yang QH, Botto LD, Gallagher M, Friedman JM, Sanders CL, Koontz D, Nikolova S, Erickson JD and Steinberg K: Prevalence and effects of gene-gene and gene-nutrient interactions on serum folate and serum total homocysteine concentrations in the United States: findings from the third National Health and Nutrition Examination Survey DNA Bank. Am J Clin Nutr 88: 232-246, 2008.

35. Guéant-Rodriguez RM, Guéant JL, Debard R, Thirion S, Hong LX, Bronowicki JP, Namour F, Chabi NW, Sanni A, Anello G, et al: Prevalence of methylenetetrahydrofolate reductase $677 \mathrm{~T}$ and $1298 \mathrm{C}$ alleles and folate status: a comparative study in Mexican, West African, and European populations. Am J Clin Nutr 83: 701-707, 2006.

36. D'Angelo A, Coppola A, Madonna P, Fermo I, Pagano A, Mazzola G, Galli L and Cerbone AM: The role of vitamin B12 in fasting hyperhomocysteinemia and its interaction with the homozygous C677T mutation of the methylenetetrahydrofolate reductase (MTHFR) gene. A case-control study of patients with early-onset thrombotic events. Thromb Haemost 83: 563-570, 2000.

37. Hustad S, Midttun $\varnothing$, Schneede J, Vollset SE, Grotmol T and Ueland PM: The methylenetetrahydrofolate reductase $677 \mathrm{C}-->\mathrm{T}$ polymorphism as a modulator of a B vitamin network with major effects on homocysteine metabolism. Am J Hum Genet 80: 846-855, 2007.

38. Sensoy N, Şoysal Y, Kahraman A, Doğan N and Imirzalioğlu N: Modulator effects of the methylenetetrahydrofolate reductase C677T polymorphism on response to vitamin B12 therapy and homocysteine metabolism. DNA Cell Biol 31: 820-825, 2012.

39. Arjona Mateos CR, Criado Velasco J and Sánches Solís L: Enfermedades crónicas y consumo de fármacos en mayores de 65 años. Medicina General 47: 684-695, 2002 (In Spanish).

40. Gonzalez-Gross M, Sola R, Albers U, Barrios L, Alder M, Castillo MJ and Pietrzik K: B-vitamins and homocysteine in Spanish institutionalized elderly. Int J Vitam Nutr Res 77: 22-33, 2007. 